\title{
Research Paper \\ A Study of Service Quality in Extension and Services Centers of Agriculture in Alborz Prov- ince Using SERVQUAL Model
}

\author{
*Omid Jamshidi ${ }^{1}$, Seyd Davoud Haji Mirrahimi², Ali Asadi ${ }^{3}$
}

1. PhD Candidate, Department of Agricultural Management and Development, Faculty of Agricultural Economics and Development, University of Tehran, Tehran, Iran. 2. Assistant Professor, Agricultural Research, Education and Extension Organization, Institute of Technical \& Vocational Higher Education, Imam Khomeini Higher Education Center for Agriculture, Karaj, Iran.

3. Professor, Department of Agricultural Management and Development, Faculty of Agricultural Economic and Development, University of Tehran, Tehran, Iran.

Citation: Jamshidi, O., Haji Mirrahimi, S. D., \& Asadi, A. (2016). A Study of Service Quality in Extension and Services Centers of Agriculture in Alborz Province Using SERVQUAL Model. Journal of Rural Research, 7(2), 330-343.

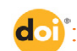

Received: 26 Dec 2015

Accepted: 08 Apr 201

Key words:

Services, Quality,

SERVQUAL, Extension

and services centers

of agriculture

\section{ABSTRACT}

The Extension and Services Centers of Agriculture aim to create the necessary basis to fulfill all the duties and responsibilities of the Ministry of Jihad-e Agriculture in rural and agricultural environments. These centers are responsible for ensuring that the farmers are continually satisfied with the services being delivered. Therefore, the main purpose of this study was to evaluate the service quality in Extension and Services Centers of Agriculture in Alborz Province using the SERVQUAL Model. This study was conducted using the survey method, and a modified SERVQUAL standard questionnaire was applied as a research tool. The validity of the instrument was confirmed by a panel of experts, and its reliability was determined by Cronbach's Alpha (over 0.7) for different scales of the questionnaire. The target population consisted of existing farmers and users visiting the seven service centers in the province. Based on Cochran's formula, the sample size was determined to be 180 persons who were chosen by random sampling method. The result of this study showed that there is a significant difference between perception and expectation in all dimensions of service quality (reliability, responsiveness, assurance, empathy, and tangibles). There was also a significant difference between the satisfaction levels of respondents with respect to the different dimensions of service quality. Finally, some recommendations have been proposed to the decrease the gap between the perception and expectation of services.

\section{Extended Abstract}

\section{Introduction}

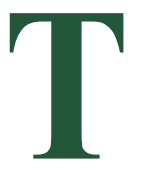

he importance of service quality in organizations dealing with a high volume of customers is rapidly growing as the effectiveness of their large investments could be wiped out due to poor service quality.
Nowadays, customer satisfaction is an essential part of every organization's survival and growth and is highly dependent on service quality. In the service sector, customer's satisfaction is very important, so quality is described as "meeting the requirements of the customer". Successful organizations have good and complete interaction with their own customers and utilize their feedbacks suitably and appropriately. The Extension and

\section{* Corresponding Author:}

\section{Omid Jamshidi, PhD Candidate}

Address: Department of Agricultural Management and Development, Faculty of Agricultural Economics and Development, University of Tehran, Tehran, Iran.

Tel: +98 (918) 3536692

E-mail: jamshidi.omid65@ut.ac.ir 
Services Centers of Agriculture aim to create the necessary basis to fulfill all the duties and responsibilities of the Ministry of Jihad-e Agriculture in rural and agricultural environments. These centers ensure that farmers are continually satisfied with the delivered services so as to attract their loyalty and confidence. However, it is important to assess whether this goal is being achieved. The survey method is one such means of customer evaluation that is widely used due to the convenience and speed of action. There are also some models to assess the delivery of service quality. The SERVQUAL model (also known as RATER) is a widely accepted quality management framework to measure quality, especially in the service sector. In this model, there are five dimensions of service quality as follows:

Reliability: The ability to perform the promised service in a dependable and accurate manner.

Responsiveness: Readiness and willingness of employees to help customers and provide timely support services.

Assurance: The knowledge and courtesy of employees and their ability to convey trust and confidence.

Empathy (Including access, communication, understanding the customer): Caring and individualized attention that the firm provides to its customers

Tangibles: Appearance of physical facilities, equipment, personnel, and communication materials.

In this study, quality is defined as the difference between customer's expected service and experienced service. It can be stated as follows:

$$
Q=P-E
$$

where, $\mathrm{Q}$ is the quality of delivered service, $\mathrm{P}$ is the customers' perception of the delivered service, and $\mathrm{E}$ is the customer's expectations of the service.

\section{Methodology}

In this descriptive study, the five dimensions of quality services were measured. The main objectives of this study were to:

1) Determine whether there is a gap between the perception and the expectation of farmers about the delivered service by Extension and Services Centers of Agriculture,
2) Determine the differences between the five dimensions of service quality.

This research determines the quality of services of seven Extension and Services Centers of Agriculture in Alborz province. The population for conducting the study consisted of existing farmers and users visiting the centers. Based on Cochran's formula, the sample size was determined to be 180 persons who were chosen by random sampling method. The SERVQUAL standard questionnaire, which was modified and adapted to increase its relevance to agricultural services, was applied to collect information. A five-point Likert scale, ranging from $1=$ strongly disagree to $5=$ strongly agree, was used to measure the expectations and perceptions of the provided services. The service quality was measured by evaluating the gap between the expectations and perceptions. In this research, reliability was determined by using Cronbach's Alpha (over 0.7) for different dimensions of the questionnaire. The SPSS18 software was used for data processing.

\section{Results}

Based on the results, 162 persons $(90 \%)$ were male and 18 persons $(10 \%)$ were female. Their mean age was 45.33 years. About $48 \%$ of the respondents were farmers and horticulturists, $33 \%$ livestock breeders, $7 \%$ greenhouse owners, and $12 \%$ belonged to other sectors. About $20 \%$ were illiterate, $42 \%$ of them were under diploma, 19\% had diploma, and 9\% had associate degree, and $10 \%$ of them had a bachelor or above degree. In the study of gap between perception and expectation, it was revealed that "responsiveness" had the most gap of all. Test of hypothesis showed that there is significant difference between perception and expectation in all 5 dimensions. Findings revealed that there are significant differences between various dimensions.

\section{Discussion}

Based on the findings, reliability, responsiveness, tangibles, assurance, and empathy were most important dimensions, respectively. In Feali et al. (2011) research, reliability, empathy, and assurance were priorities. Findings showed that there is a significant difference between perception and expectation of farmers. In other words, expectation of farmers was higher than their perception. Findings of Rahim (2011), Cody and Hope (1999), Saraie and Amini (2012), Osei et al. (2012), Enayati Novinfar et al. (2011), Ranjbar Ezatabadi (2010) and Gorji (2009) were similar to this study results. 


\section{Conclusion}

To reduce gap in services, the centers should improve their services to increase users' satisfaction. Greater investments in infrastructure and the quality human resources in centers could enable them to expand coverage and enhance services for the majority of the farming population. Furthermore, the centers should step ahead towards new paradigm of performance and achievement through quality management, which will enhance service impact and results in delivering better service. 


\title{
سنجش كيفيت خدمات مراكز خدمات ترويج كشاورزى با استفاده از مدل سِرؤكوال در استان البرز
}

\author{
"اميد جمشيدى'، سيداوود حاجىميررحيمى'، على اسدى"
}

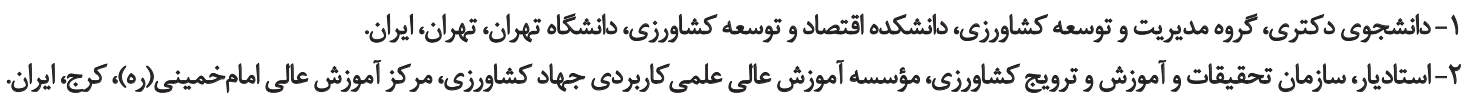

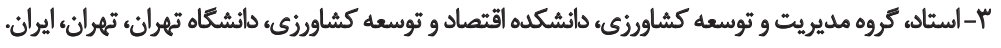

\begin{abstract}
حكيد

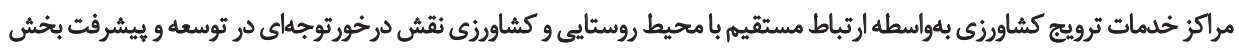

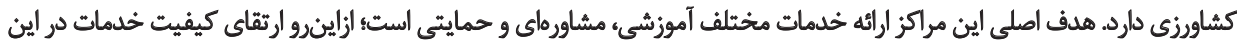

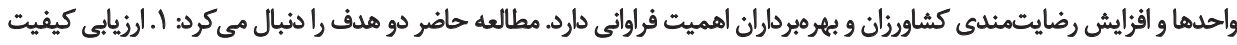

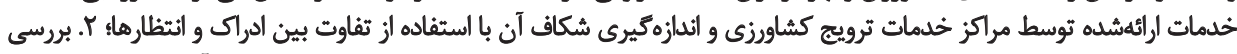

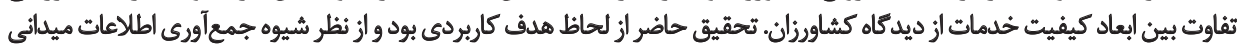

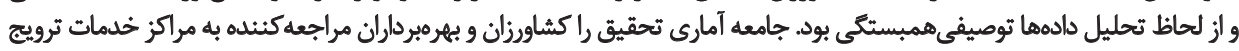

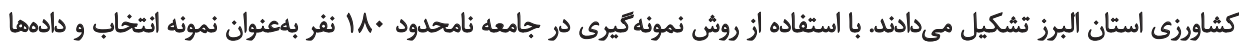

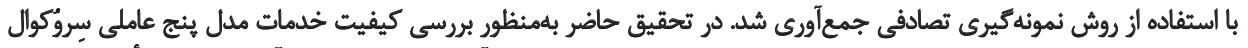

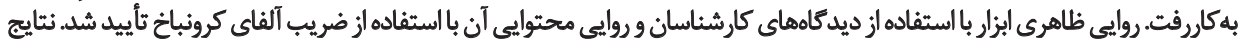

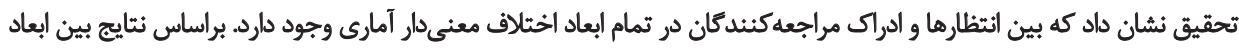

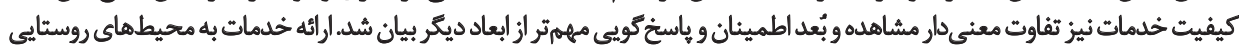

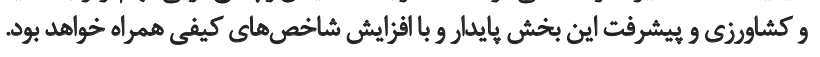

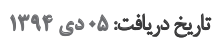

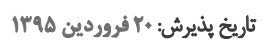

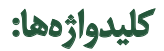

خدمت، كيفيت، سِروكوال، مراكز خدمات تَرويج كشاورزى ماكن خدمان

بهنوان متولى اصلى بخش كشاورزى كشور، مراكز خدمات ترويج

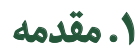

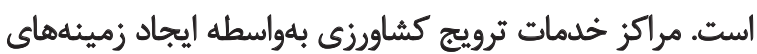

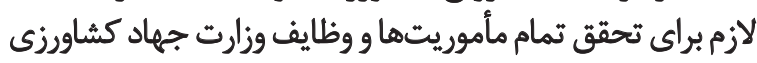

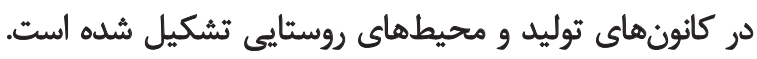

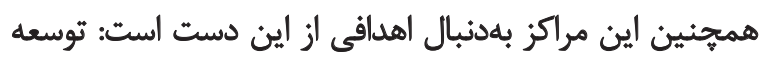

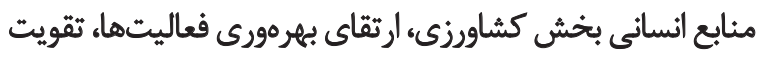

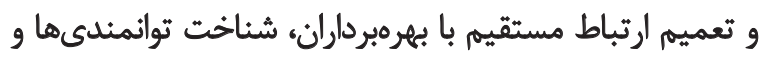

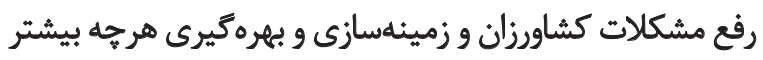
از مشاركت بهرهبرداران. - ان.

همانكونه كه از وظايف تعريفشده براى مراكز اشارهشده

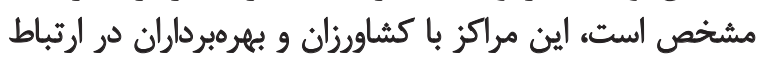

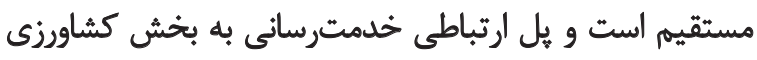

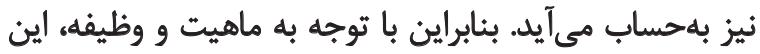

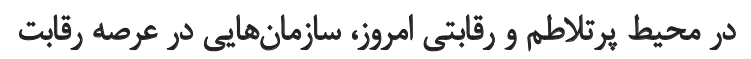

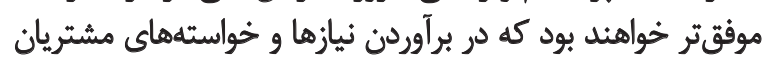

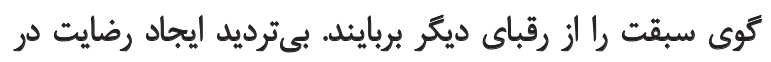

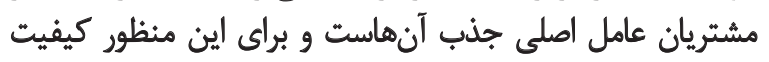

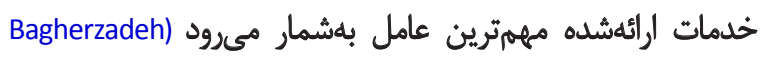

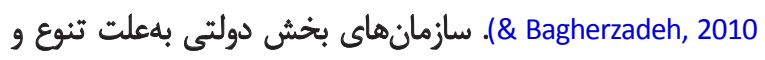

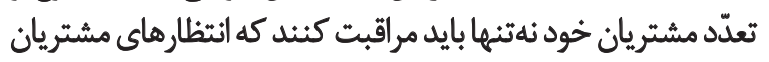

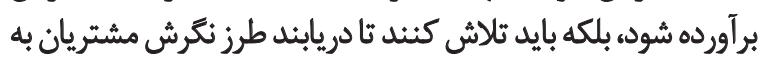

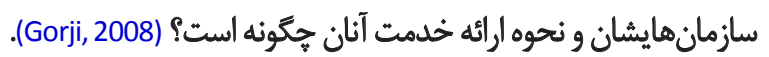

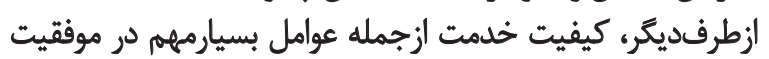
سازمانهاى خدماتى است (Rana, Reddy, \& Sontakki, 2013). يكى از مهمثرين بخشهاى خدماتى وزارت جهاد كشاوزى 


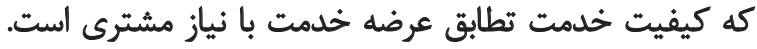

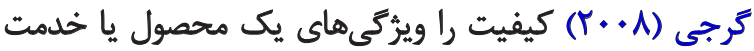

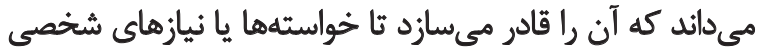

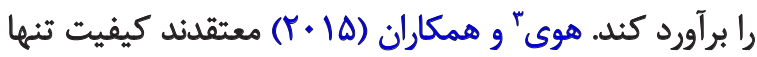

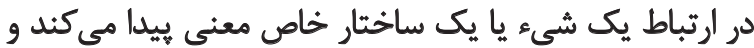

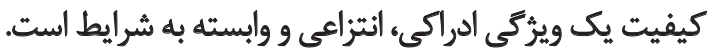

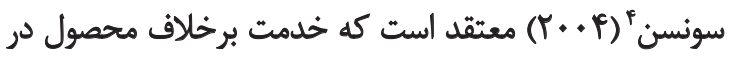

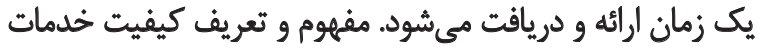

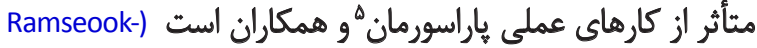

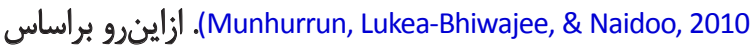
تعريف هاراسورمان و همكاران، كيفيت خدمت عبارت است از درجه

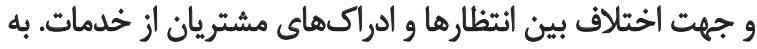

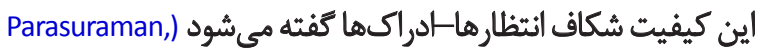

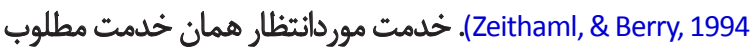

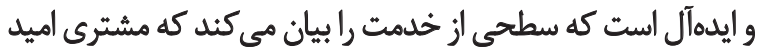
دريافت آن را دارد (Beatson, Lings, \& Gudergan, 2008).

درحقيقت خدمات مطلوب ثلفيقى از باورهاى مشترى درباره

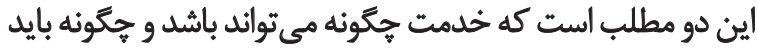

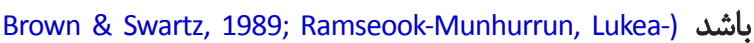
Bhiwajee, \& Naidoo, 2010; Osei Mensah, Owusu Damoah, \& (Aidoo, 2012 مشترى اغلب كيفيت خدمات را با مقايسه بين

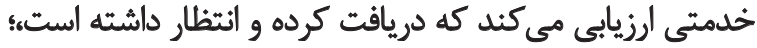

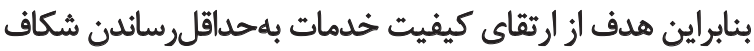

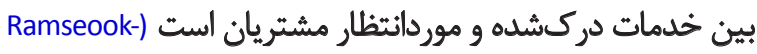
.(Munhurrun, Lukea-Bhiwajee, \& Naidoo, 2010

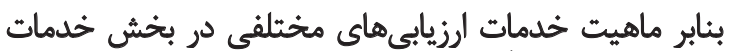

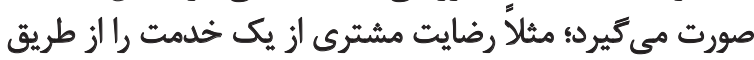

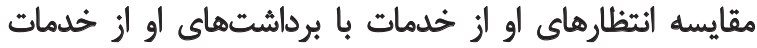

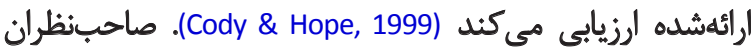

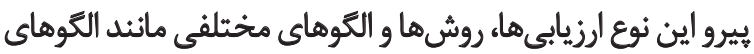

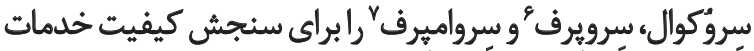

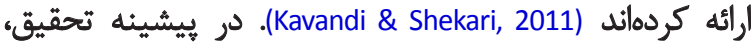

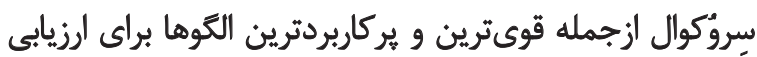
كُيفيت خدمات بهشمار مي آيد (Osei Mensah et al., 2012).

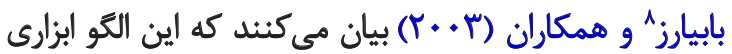
مناسب براي شناسايى و تصحيح فاصله بين سطوح واقعى و آرمانى
3. Huy
4. Svensson
5. Parasuraman
6. Servperf
7. Servimperf
8. Babiarz

مراكز بهدنبال ارائه خدمات مرثبط باكيفيت و درنهايت اقزيش

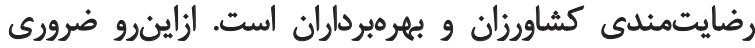

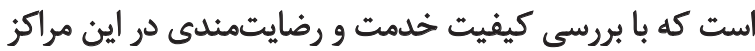

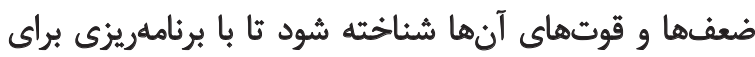

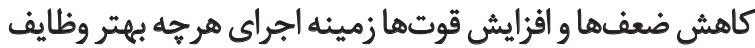

$$
\text { سير دهده فراهم شود. }
$$

با توجه به اينكه اين مراكز در صف نخست ارتباط با كشاورزان

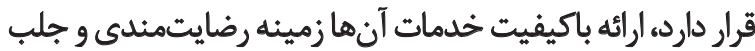

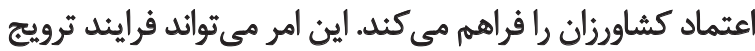

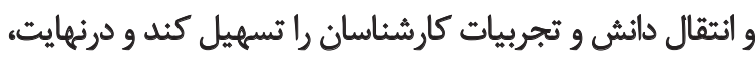

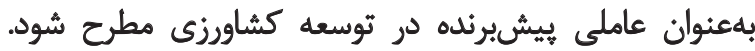

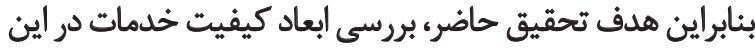

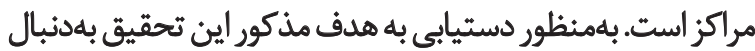

$$
\text { ياسخ به اين يرسش هاست: }
$$

ا. آيا بين سطح انتظارهاى كشاورزان از مؤلفههاى مراكز خدمات ترويج كشاورزى (مانئ عوامل ملموس، تضمين، قابليت

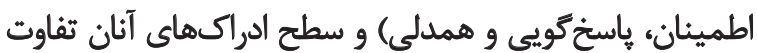
وجود دارد؟ اطمينان r. آيا از ديد مراجعهكنئدكان بين ابعاد ينج كانه كيفيت از نظر

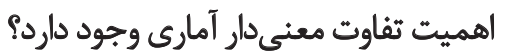
كفتنى است ثاكنون تحقيقات اندكى به بروسى كيفيت

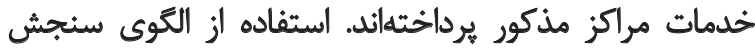

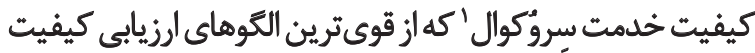

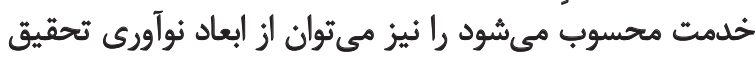
حاضر بهشمار آورد.

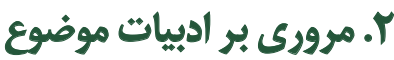

مطالعات بسيارى نشان دادهاند كه ارائه خدمات با كيفيت

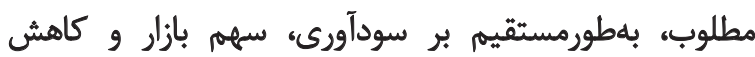

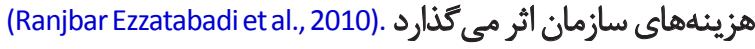

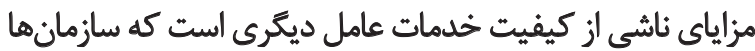

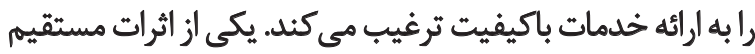

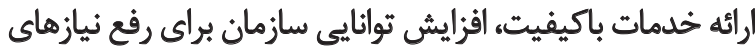

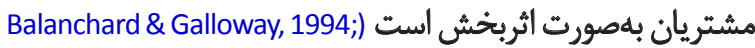
.(Mirfakhradini, Mirfakhradini, \& Sadr Bafghi, 2013

كيفيت خدمات هفهومي الست كه ثاكنون تعاريف متعددى از

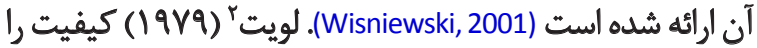

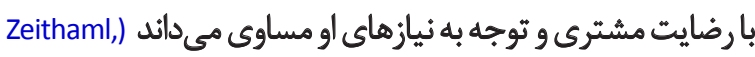

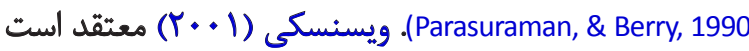

1. SERVQUAL

2. Levit 
قيمت محسوس و قيمت خدماتى، اعتبار و راحتى خلاصه

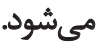

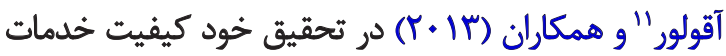

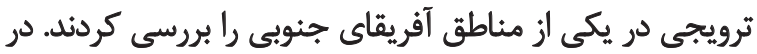

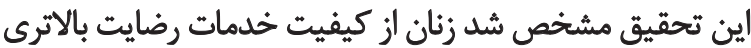

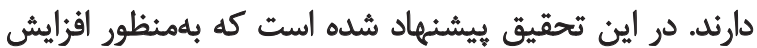

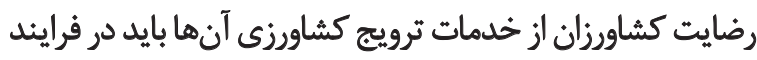

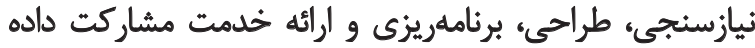

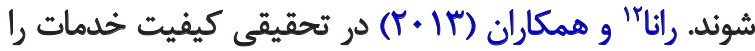

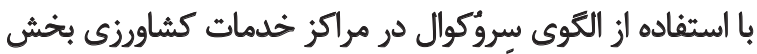

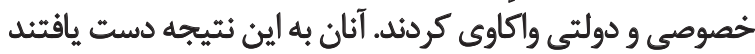

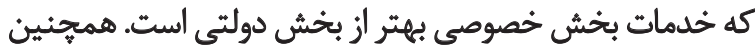

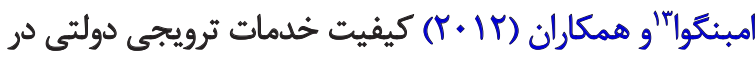
آفريقاى جنوبى را بررسى كردند.

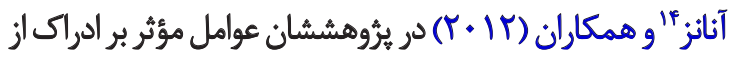

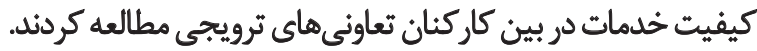

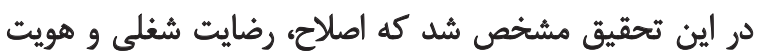

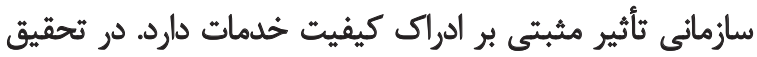

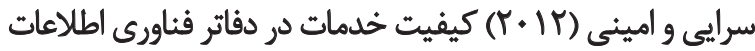

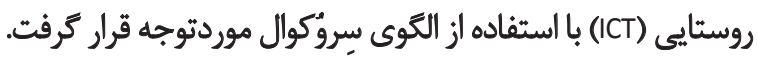

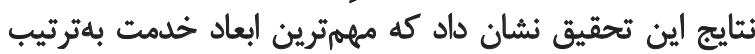

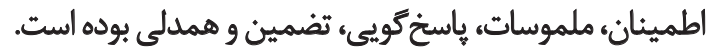

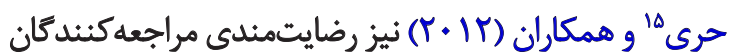

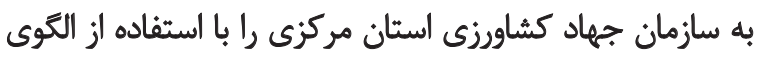

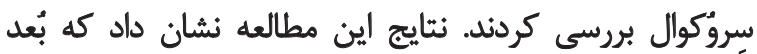

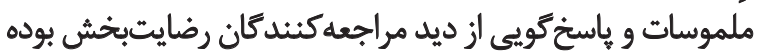

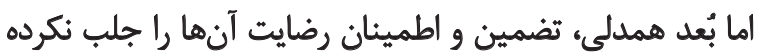

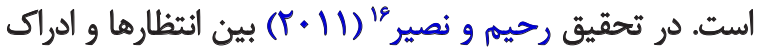

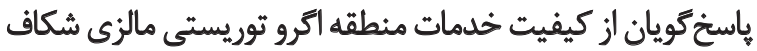

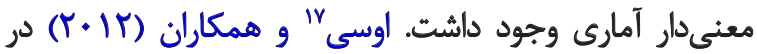

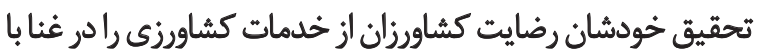

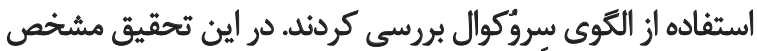
شد كشاورزان از خدمات ارائهشده رضايتمندى بردي بسيار كمى دارند.

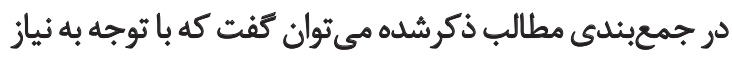

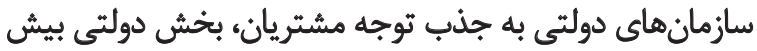

11. Agholor

12. Rana

13. Mmbengwa

14. Ananz

15. Horri

16. Rahim and Nasir

17. Osei

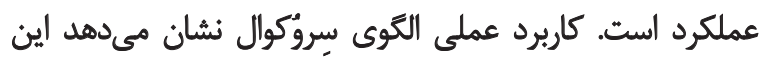

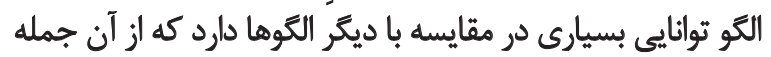

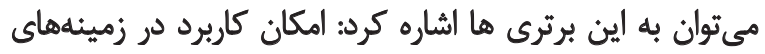

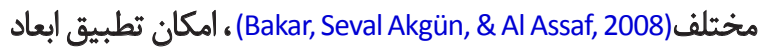

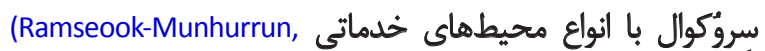
LLkea-Bhiwajee, \& Naidoo, 2010) (Osei Mensah et al., مقايسه با ادراكها و انتخان

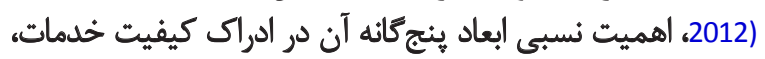

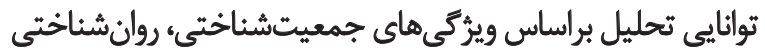

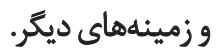

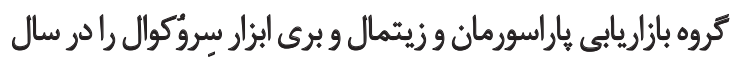

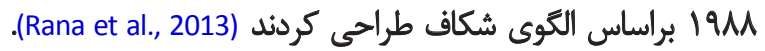

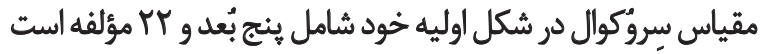

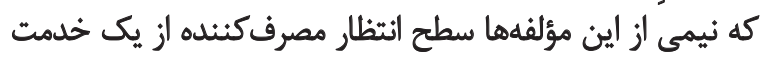

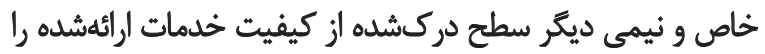

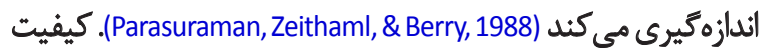
خدمت بهوسيله تفاضل بين نمرات، سطح ادراك و سطح موردانتئنار

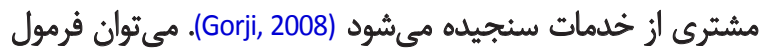
كيفيت خدمات را بهشرح زير بيان كرد: $E-P=Q$

= = $=$

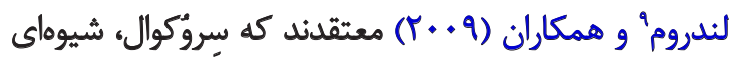

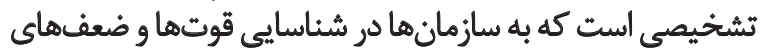

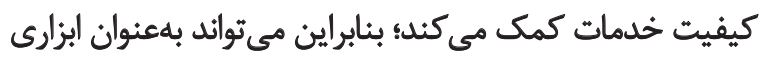

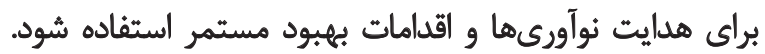

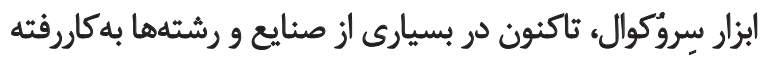

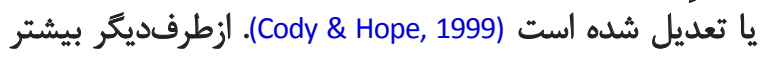

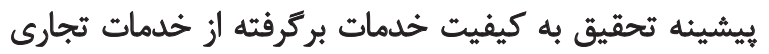

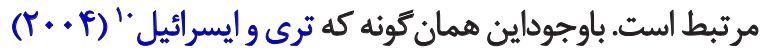

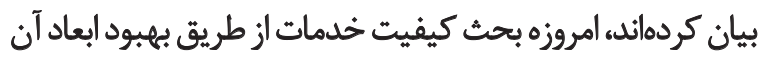

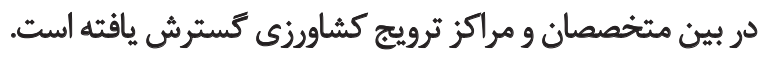
در بحث كيفيت خدمات، تاكنون تحقيق كستردهاى انجام

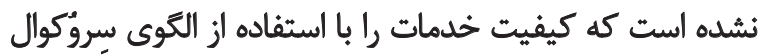

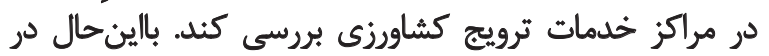

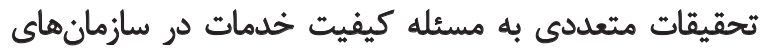

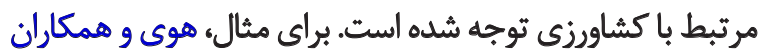

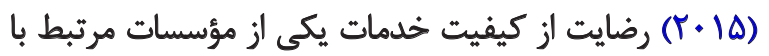

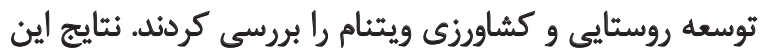

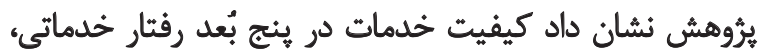

9. Landrum

10. Terry and Israel 


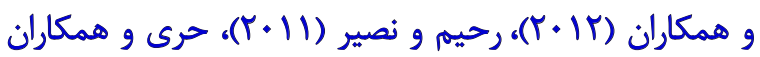

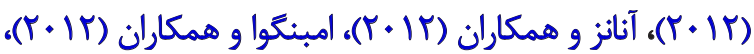

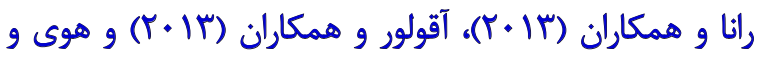

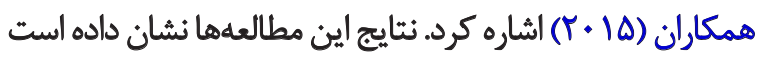

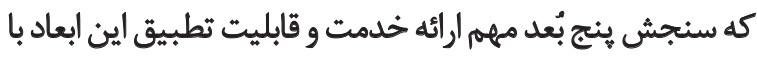

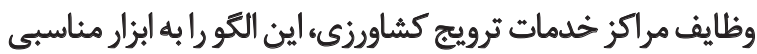

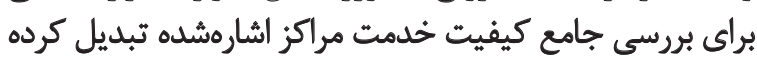

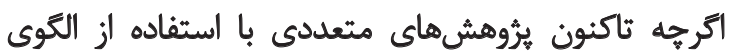

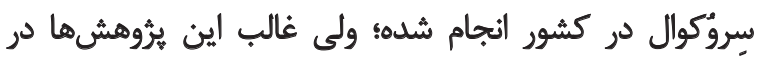

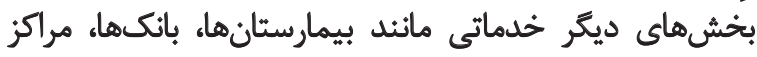

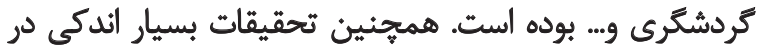

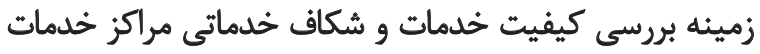

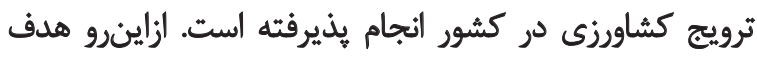

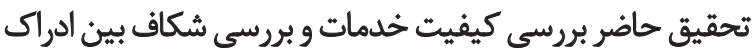

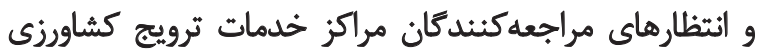
استان البرز با استفادهاز الكوى سِروُوكوال است.

تحقيق حاضر از نظر هدف، كاربردى و روش استفادهشده در

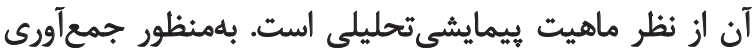

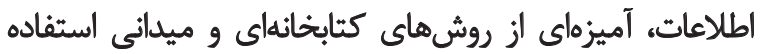

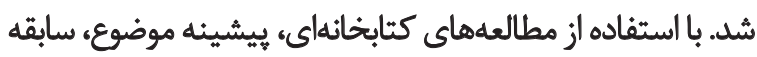

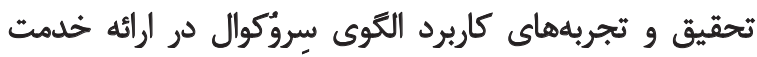

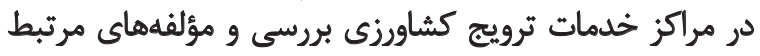

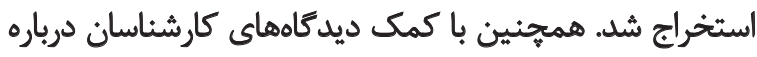

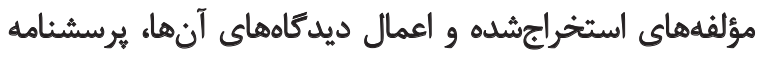

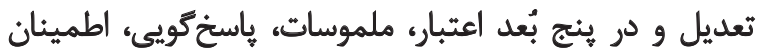

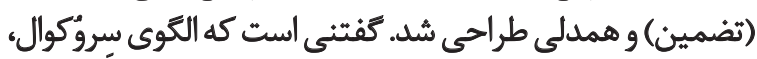

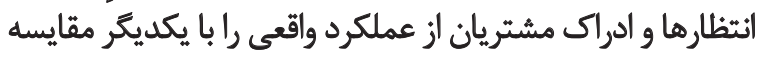

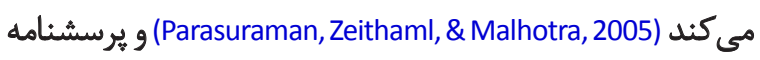

از كذشته در بيى اندازهيرى كيفيت خدمات خود است. مشكل

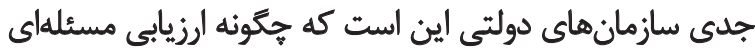

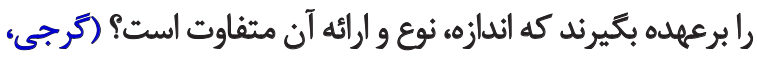

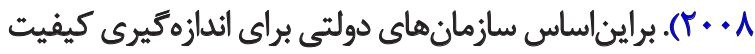
خدمات خود به التوهاى تعريفشانده نياز دارند. برائ

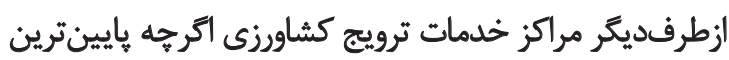

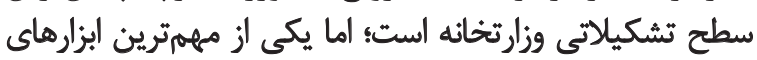

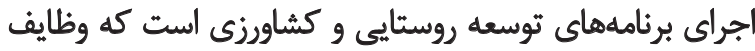

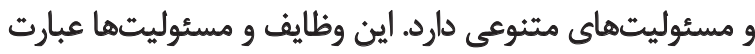

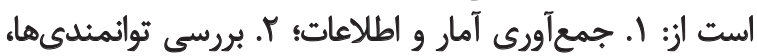

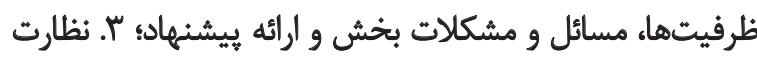

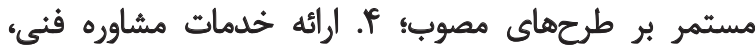

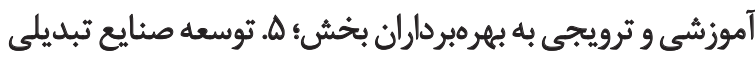

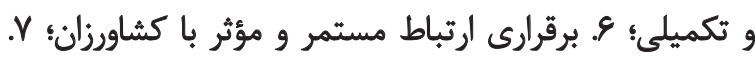

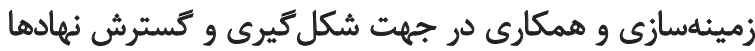

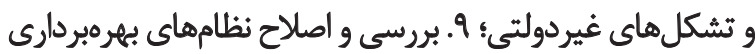

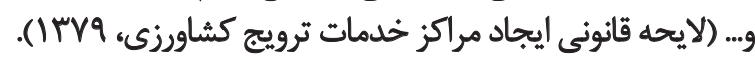

حوزه كسترده وظايف و مسئوليتهاي سيردهشده به به اين مراكز

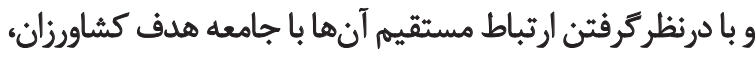

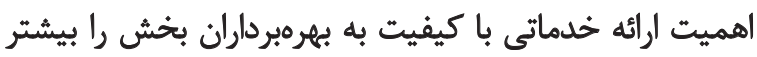

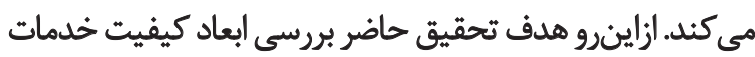
مراكز ترويج كشاورزى در استان البرز است.

$$
\text { ب. ب. روش شناسى تحقيق }
$$

خمان كونه كه ذكر شدسِروُكوال يكى از الكوهاى سنجش كيفيت

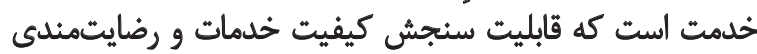

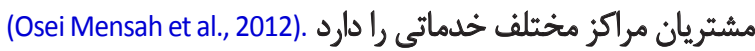

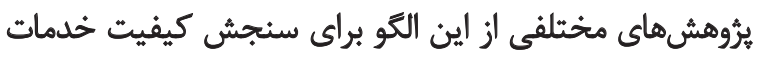

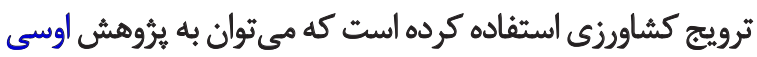

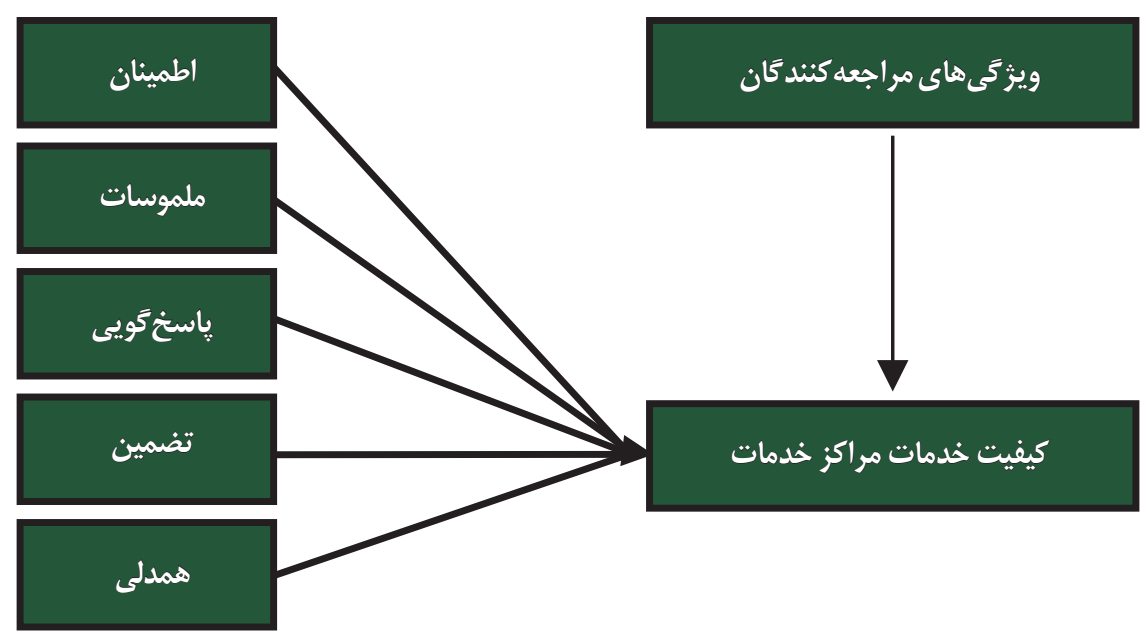


جدول ا. ياياييى ابعاد يرسشنامههاي انتظارها و ادراكها.

\begin{tabular}{|c|c|c|}
\hline \multicolumn{2}{|c|}{ آلفاي كرونباخ } & \multirow{2}{*}{ ابعاد سِوروكوال } \\
\hline يرسشنامه ادراكها & يرسشنامه اثتظارها & \\
\hline$\cdot / N$ & . /Na & ملموسات \\
\hline.$/ V E$ &.$/ 199$ & اطمينان \\
\hline$\cdot|\Lambda|$ &.$/ M \lambda$ & ياسخ كويى \\
\hline . /AT & $\cdot / \Lambda \Delta$ & تضمين \\
\hline - /AT & $+|A|$ & هملىى \\
\hline
\end{tabular}

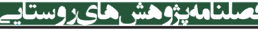

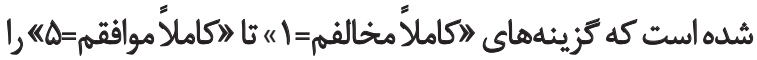

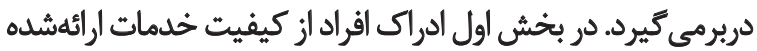

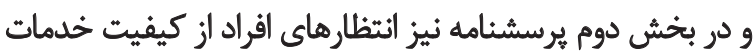

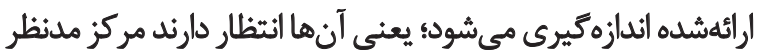
در اين كزينه خاص از ها ميز ميزان كيفيتى برخوردار باشند.

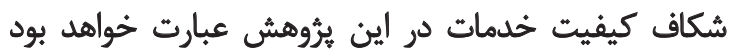

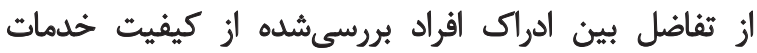

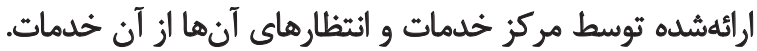

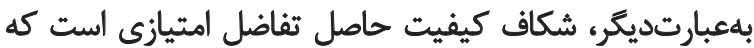

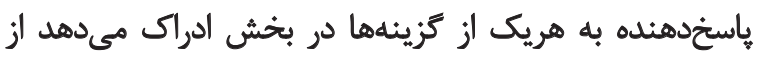

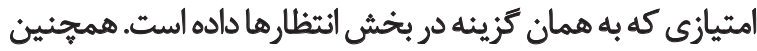

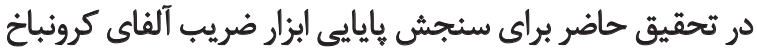

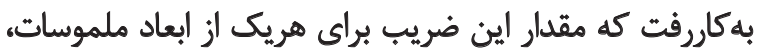

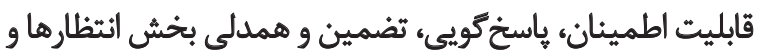

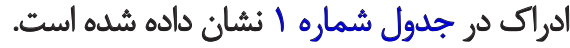

جامعه آمارى اين يثوهش مراجعهكنيندكان به مراكز خدمات

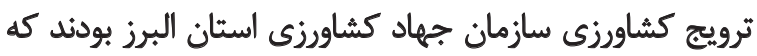

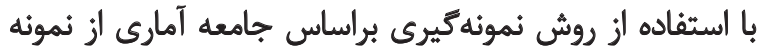

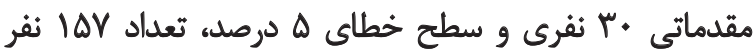

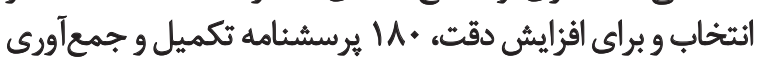

تحقيق نيز مبتنىبر اين الكوى طراحى شده است (تصوير شماره

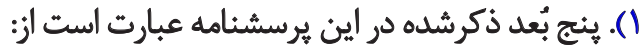

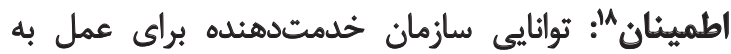
وعدهاى خود بهطور دقيق و مستمر؛ ملموسات" "ظاهر تسهيلات و تجهيزات فيزيكى و ابزارآلات، ظاهر كاركنان و ابزار برقرارى ارتباط با سازمان؛

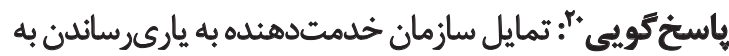

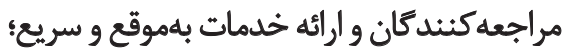
تضمين"ا دانش و ادب كاركنان و توانايى آنها در ايجاد اعتماد و اطمينان و تضمين خدمات؛ كان

همدلى "آ: نزديكى و همدلى بامراجعه كئندان ودرك و توجه

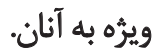

اين برسشنامه شامل دو بخش ادراك و انتظارهاست. براى

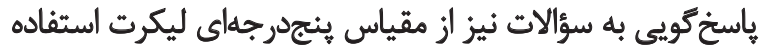

\section{Reliability}

19. Tangibles

20. Responsiveness

21. Assurance

22. Empathy

جدول r. توزيع نمونه تحقيق.

\begin{tabular}{|c|c|c|}
\hline نسبث نمونه (درصد) & تعداد نمونه & نام مركز \\
\hline ro & PD & سيفـآباد \\
\hline$I V / r$ & m & تنكمان \\
\hline $19 / \pi$ & rq & أسارا \\
\hline$r \% / \mu$ & Rt & طالقان \\
\hline$W^{w}$ & m & 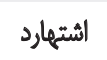 \\
\hline $1 .$. & $\mathrm{M}$. & جمع \\
\hline
\end{tabular}


مختلف و مؤلفهها براساس شكاف بين انتظارها و ادراى رانشان

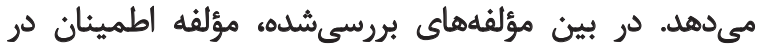

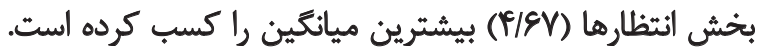

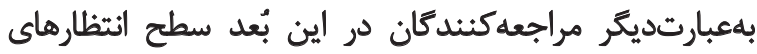

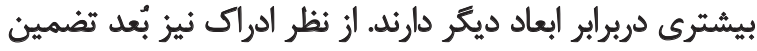

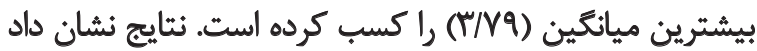

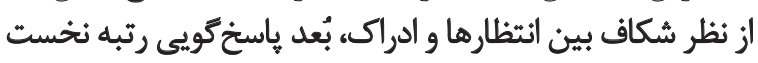

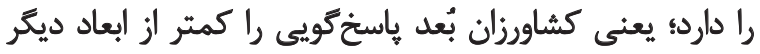

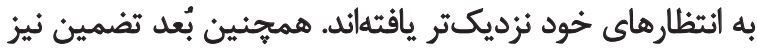

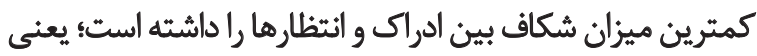

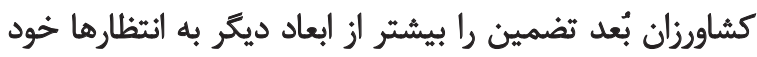
نزديكتر يافتهاند (تصوير شماره ب).

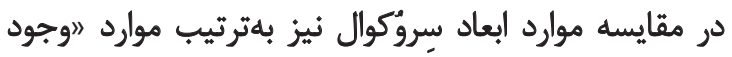

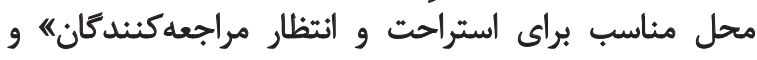

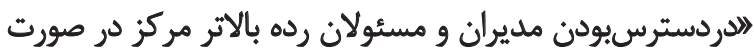

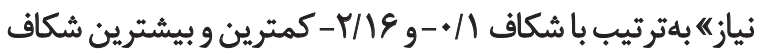

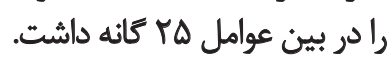

در تحقيق حاضر براي بررسي تفاوت ميزان انتظارها و ادراك

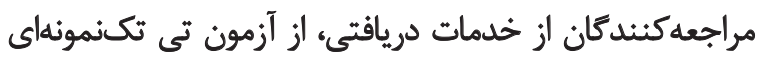

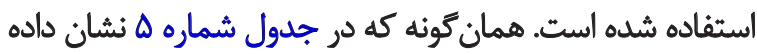

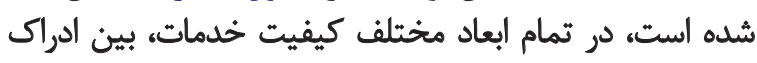

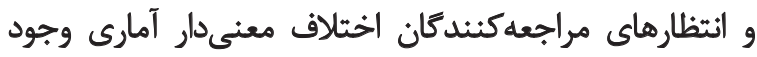

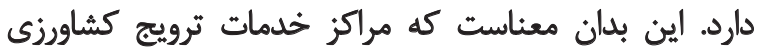

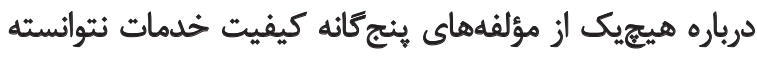

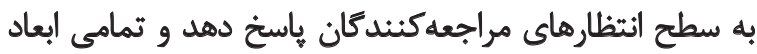

شد. كُفتنى است كه استان البرز سه مركز خدمات ترويج

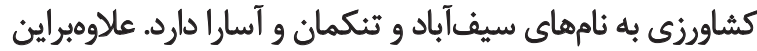

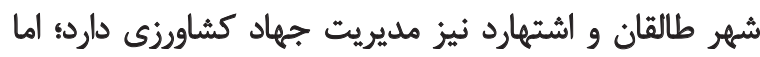

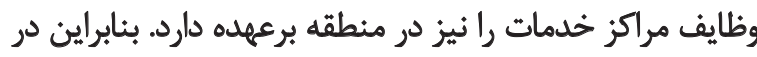
تحقيق حاضر شرح نمونه كيرى از مراكز نامبرده در جدول درائ شماره

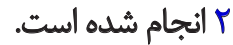
روش نمونه حيرى تحقيق نيز بهصورت كاملاً تصادفى بود. در

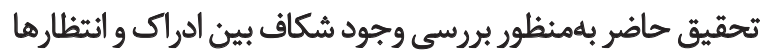

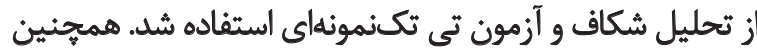

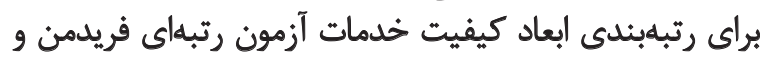

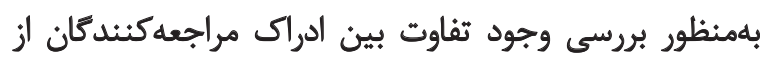
مراكز مختلف خدمات ترويج كشاورزى استان نيز تحليل واريانس برانس

$$
\text { يكسرفه بr به كارفت. }
$$

f

نتايج توصيفى تحقيق در جدول شماره ب نشان داده شده

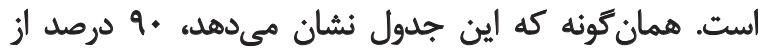

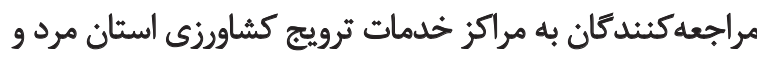

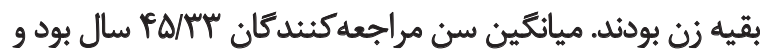

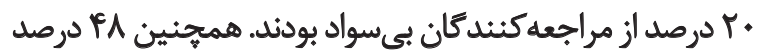

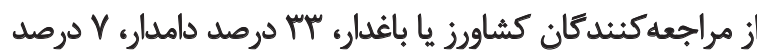

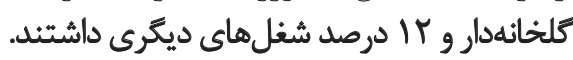

جدول شماره f ميانكين انتظارها و ادراك و رتبلبندى ابعاد

23. ANOVA

جدول ب. يافتههاى توصيفى يُوهش.

\begin{tabular}{|c|c|}
\hline تروه & متغير \\
\hline زرد=+ج درصد (باع| نفر) & جنسيت \\
\hline 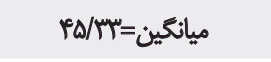 & سن (سال) \\
\hline 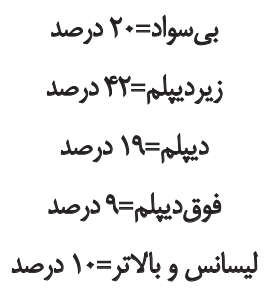 & تحصيلات \\
\hline 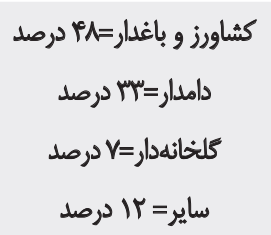 & وضعيت شغلى \\
\hline
\end{tabular}


جدول F. ميانكين انتظارها و ادراكها و رتبهبثدى ابعاد مختلف و مؤلفهها براساس شكاف بين انتظارها و ادراكها.

\begin{tabular}{|c|c|c|c|c|c|c|}
\hline $\begin{array}{l}\hat{3} \\
\frac{3}{3} \\
\frac{3}{3}\end{array}$ & $\begin{array}{l}3 \\
3 \\
3 \\
3 \\
3 \\
9\end{array}$ & 苟 & $\begin{array}{l}\frac{9}{3} \\
\frac{5}{3} \\
\frac{3}{5} \\
\frac{3}{3}\end{array}$ & 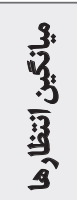 & ابعاد مختلف كيفيت خدمات & \\
\hline \multirow{8}{*}{1} & 1 & $-r / S$ & $T / \Delta \varphi$ & $P / M$ & دردسترسبودن مديران و مسئولان رددبالاتر مركز در صورت نياز & \multirow{8}{*}{ है } \\
\hline & r & $-\mathrm{l} / \mathrm{Ar}$ & $r / 9)$ & $\varphi / V \Delta$ & ياسخ كويى سريع كاركنان به خواستهها و شكايتهاى مراجعه كند بان & \\
\hline & r & $-\mid / \wedge)$ & $r / \lambda F$ & $r / 80$ & دردسترسبودن كاركنان در زمان ارائه خدمت & \\
\hline & r & $-1 / \& 8$ & 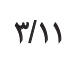 & $H / W$ & وقت كافى كاركنان براى رسيدكى به كار مراجعلكنندكان & \\
\hline & $\Delta$ & $-1 / M$ & $r / T$ & $H / \Delta \Delta$ & ارائه خدمات سريع و بلموقع به مراجعهكندكان & \\
\hline & $\varepsilon$ & $-V / \pi$ & $\Gamma / \Delta$. & $f / M^{\prime}$ & ارائه اطلاعات درست و كافي از طرف كاركنان به مراجعهكندكان & \\
\hline & \multirow[t]{2}{*}{$\checkmark$} & $-1 / r$ & $\Pi / 1$ & $\varphi / m$ & كارايى خلمات مشاوره & \\
\hline & & $-1 / 8$ & 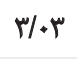 & thep & ميانكين كل & \\
\hline \multirow{6}{*}{ r } & 1 & $-1 / M$ & r/q T & $\varphi(\lambda)$ & ارائه خدمت در زمان تعيين شده & \\
\hline & r & $-V / \Delta r$ & T/TQ & $\varphi / W$ & ارائه خلمات بلون اشتباه و در صورت وقوع أشتباه رفع سريع آن & \\
\hline & $r$ & $-1 / k 8$ & $r / T^{2}$ & pleg & 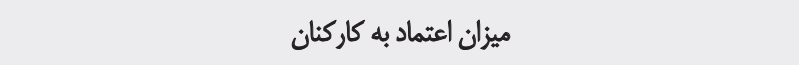 & \\
\hline & f & $-\cdot / M^{e}$ & T/VA & r/ar & رغبت صادقائه كاركنان در حل مشكل مراجعه كثندكان & \\
\hline & \multirow[t]{2}{*}{$\Delta$} & -.198 & $4 \%$ & Plev & ارائه با حوصله مشاورهها و رويههاي اثجام كار با شيوهاي واضح براي مراجعه كثندكان & \\
\hline & & $-1 / 41$ & T/FV & $r / e q$ & 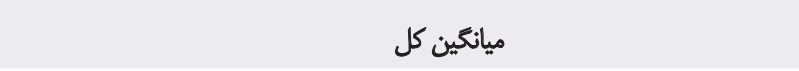 & \\
\hline \multirow{5}{*}{ r } & 1 & $-1 / 41$ & T/Q & e/pere & مناسبودن مكان هركز خذمات از لحاظ رفتوآمد & \multirow{5}{*}{ ह } \\
\hline & r & $-1 / 7 \Delta$ & r/q & T/R & مناسبودن ساختمان و هيدمان مركز & \\
\hline & $r$ & $-1 / \pi r$ & $r / r+$ & F/F & مرتببودن ظاهر و يوشش كاركنان & \\
\hline & \multirow[t]{2}{*}{ f } & -4 & $m / 1$ & $m / 1$ & وجود محل مناسب براى استراحت و انتظار مراجعه كنثدكان & \\
\hline & & $-1 /$ & $\mathrm{m} / \cdot \mathrm{r}$ & $\varphi+\varphi$ & ميانكين كل & \\
\hline \multirow{6}{*}{$f$} & 1 & $-1 / 49$ & T/M & $H / Y)$ & درى نيازهاى ويرُه مراجعه كنتدكان توسط كاركنان & \multirow{6}{*}{$\xi$} \\
\hline & r & $-1 / 4 a$ & $\psi / \cdot 1$ & t/fe & توجه خاص كاركنان و مدير به هريك از مراجعهكنتدكان & \\
\hline & r & $-+/ 79$ & WIE & $r / f Q$ & درى كافى كاركنان از مشكلات مراجعهكندكان & \\
\hline & r & -.189 & $M / \Delta F$ & H/M & ارائه خلمات به صورت راحت و بدون تنش به مراجعهكندكان & \\
\hline & \multirow[t]{2}{*}{$\Delta$} & -.189 & $f / r)$ & $f / A V$ & ساعات كارى مناسب براى ارائه خلمت & \\
\hline & & $-1 / 4$ & $r / \Delta T$ & $r / \Delta P^{e}$ & ميانكين كل & \\
\hline \multirow{5}{*}{$\Delta$} & 1 & $-1 / \cdot 9$ & TR/ & $p / p q$ & حسن اعتماد ناشى از رفثتار صحيح كاركنان و مدير مركز & \multirow{5}{*}{ 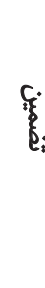 } \\
\hline & $r$ &.$- / V \Delta$ & r/eV & P/RT & احساس امنيت مراجعه كنندكان در تعاملات و كرفتن خدمت از مركز & \\
\hline & $r$ & $-\cdot / r q$ & $r / u$ & $\varphi / M P$ & دانش و مهارت كافى كاركنان و مدير در زمينه تخصصى مرتبط & \\
\hline & $p$ & $-\cdot / M$ & $\varphi$ & PRT & رؤثار مؤدبانه كاركثان و مدير با مراجعه كثندكان & \\
\hline & & $-+/ \&$ & $r / v q$ & $f / F i$ & 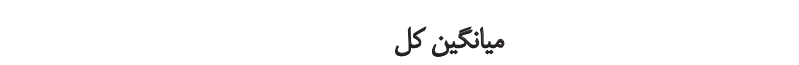 & \\
\hline
\end{tabular}

ترويج كشاورزى، آزمون فريدمن بهكار فتته كه نتايج آن در جدول

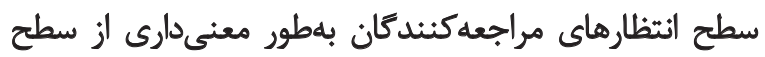

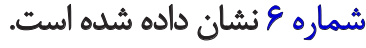

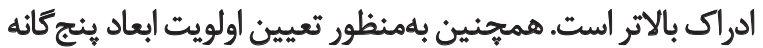
كيفيت خدمات از ديدكاه مراجعهكنيندكان به مراكز خدمات العات بنات 


\section{ه. بحث و نتيجه كيرى}

از ديد عملى اين مطالعه برآن بود كه يافتههاي حاصل از ارزيابى

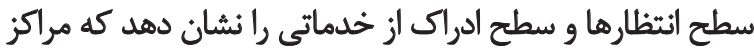

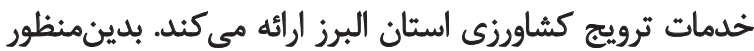

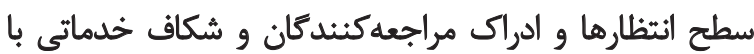

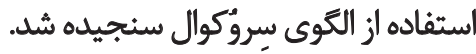
يافتههاي يُروهش حاضر نشان داد بين كيفيت موردانتظار

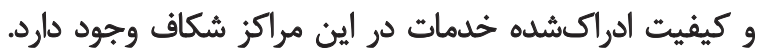

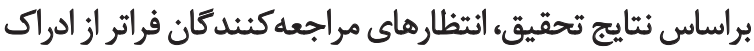

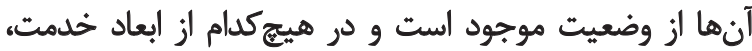

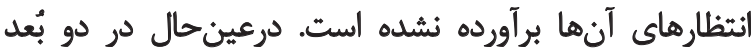

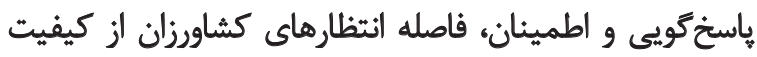

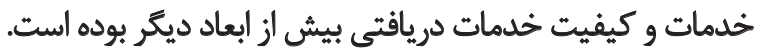

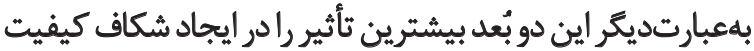

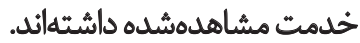

در تحقيق حاضر نتايج رتبهبندى عوامل كيفيت خدمات نشان

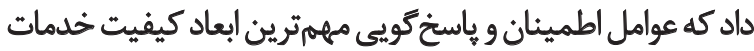

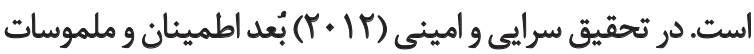

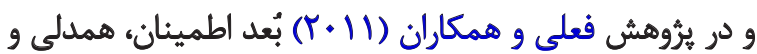
تضمين بهترتيب مهمترين ابعاد كيفيت خدمات شناخته شد.

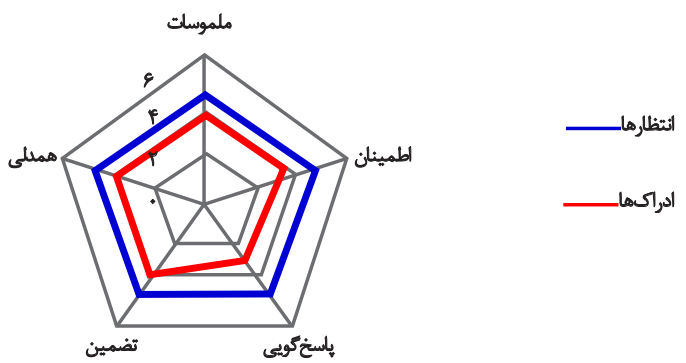

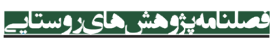

$$
\text { تصوير Y. شكاف خدمات مراكز ترويج كشاورزى استان البرز. }
$$

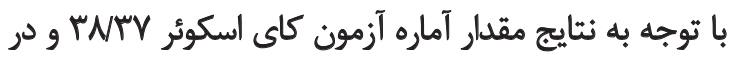

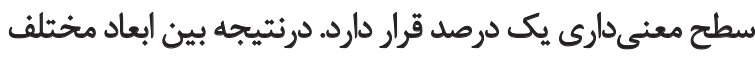

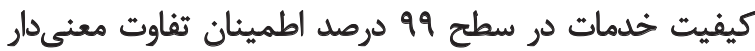

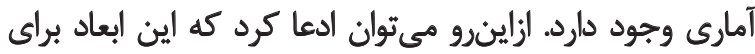

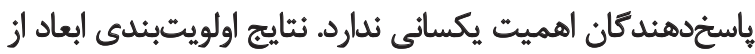

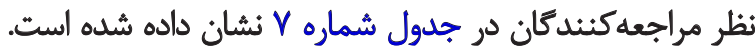

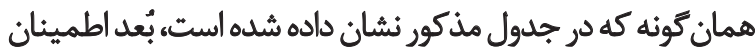

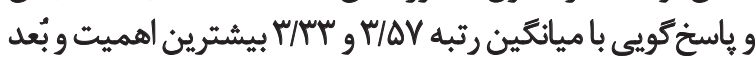

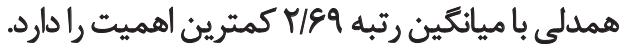

جدول ه. نتايج آزمون استنباطى تى در مقايسه بين ادراكها و انتظارهاى مراجعه كثندكان به مراكز خدمات ترويج كثاورزى.

\begin{tabular}{|c|c|c|c|c|c|c|}
\hline ميانعين ابعاد & تضمين & همدلى & اطمينان & ياسخ كَويى & ملموسات & مؤلفههاى سنجيدهشده \\
\hline WMI & $N \Delta S$ & $9 / \pi$ & $1 \% / \cdot 1$ & $M / M r$ & WW & t t مقدار \\
\hline 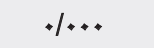 & . & $.1 \cdot 1$ & $\% 1$ &.$\ldots$ &.$\ldots$ & P-value \\
\hline
\end{tabular}

:

جدول وه نتايج آزمون فريدمن براى تعيين اولويت ابعاد ينج كانه كيفيت حُمت.

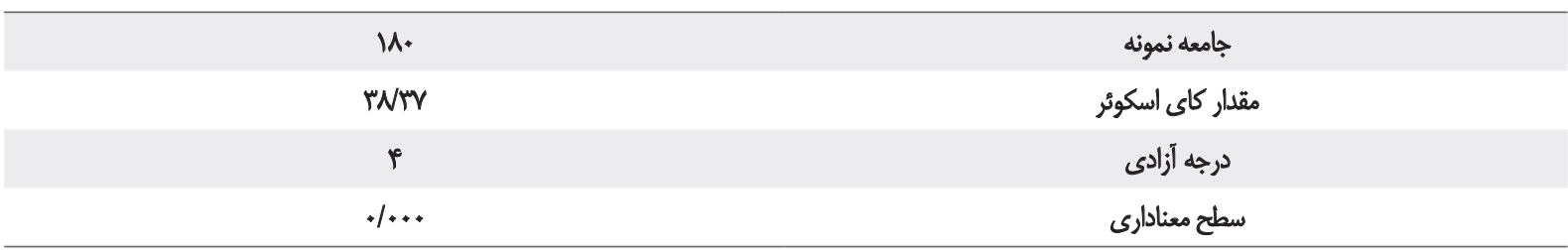

جدول V.اولويتبئدى ابعاد ينج كائه كيفيت خدمات.

\begin{tabular}{|c|c|c|}
\hline اولويت & ميانكين رثتبهاي & ابعاد ينج كاثه كيفيت \\
\hline 1 & $r / \Delta V$ & اطمينان \\
\hline r & سד/ & ياسخ كويي \\
\hline$r$ & $m / .1$ & ملموسات \\
\hline$f$ & $r / 9 \Delta$ & تضمين \\
\hline$\Delta$ & $r / e q$ & همدلي \\
\hline
\end{tabular}




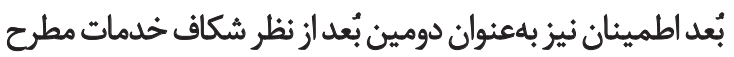

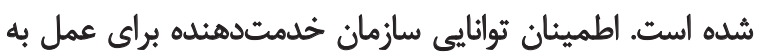

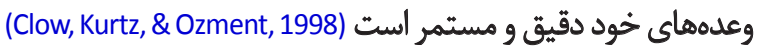

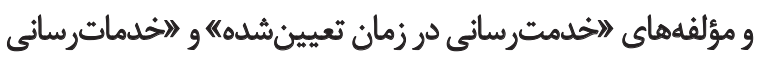

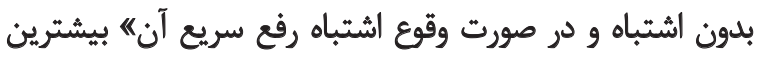

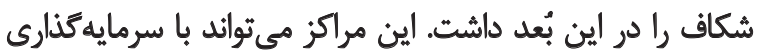

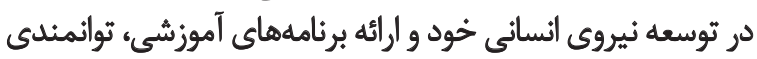
كاركنان را افزايش دهد (Rahim \& Nasir, 2011)

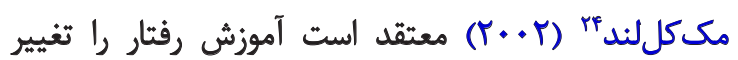

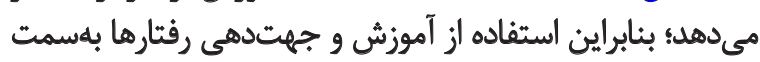

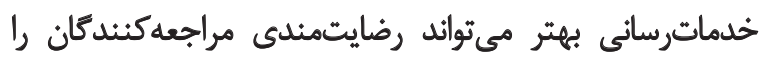

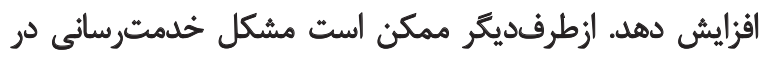

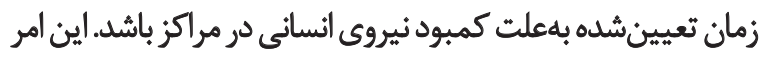

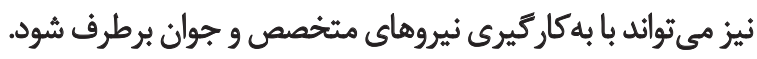

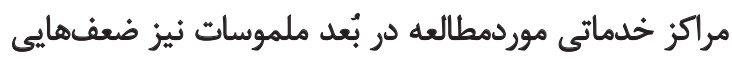

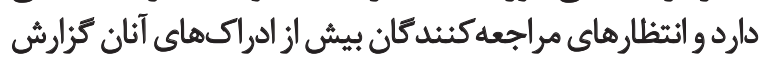

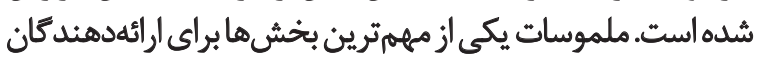

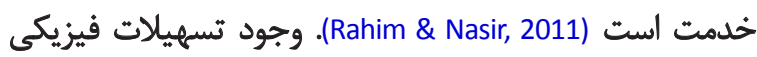

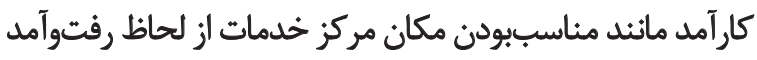

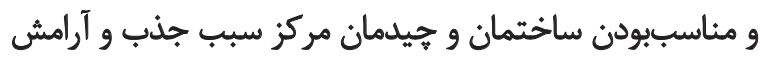

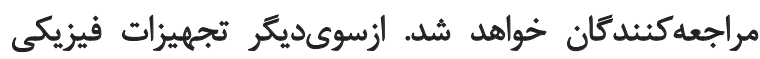

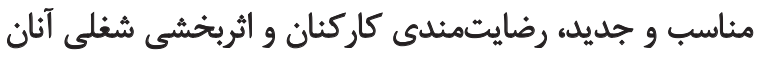
را افزايش مى مهد.

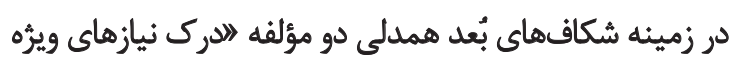

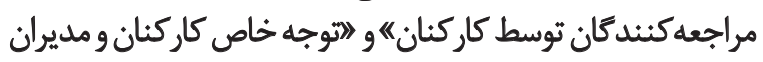

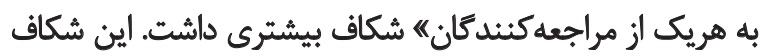

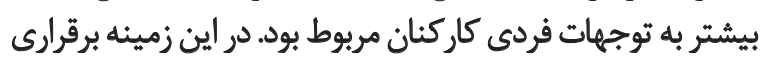

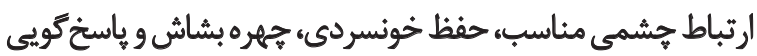

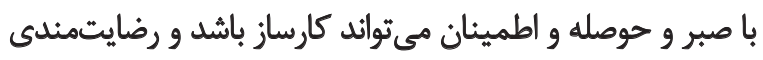
مراجعهن كند مان را افزايش دهد (Rahim \& Nasir, 2011).

در تحقيق حاضر در بُعد تضمين كمترين ميزان شكاف ديد ديده

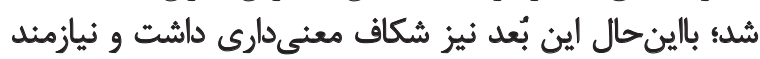

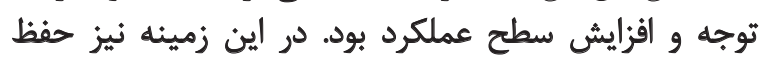

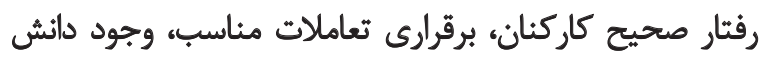

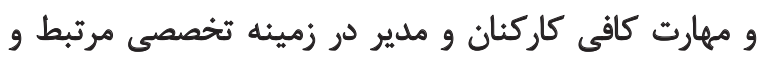

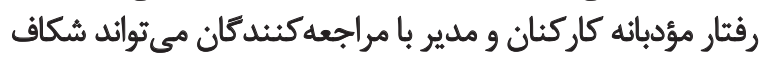

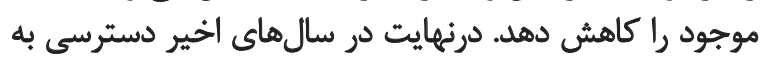

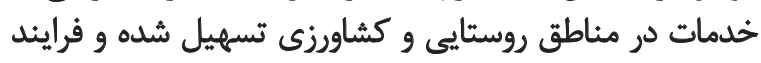

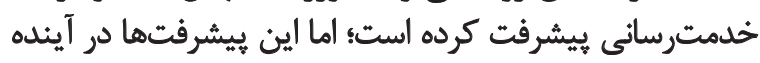

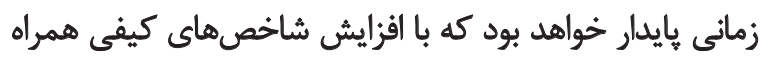

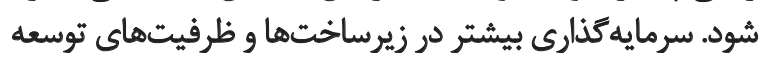

رضايتمندى از خدمث، بخش ضرورى رشد و و توسعه مازئ

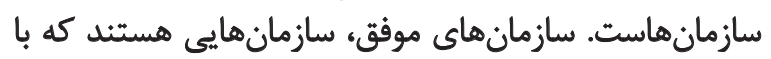

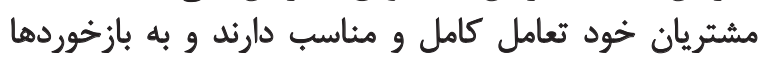

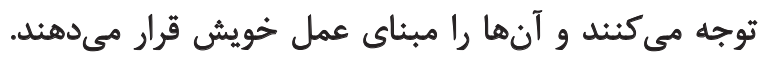

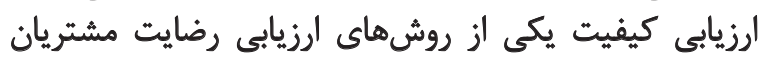

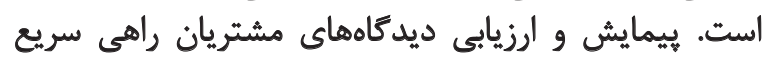

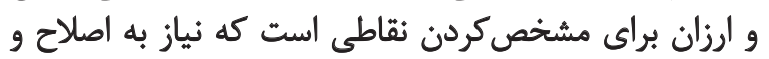

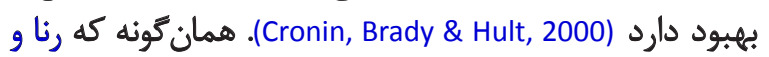

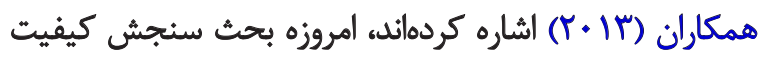

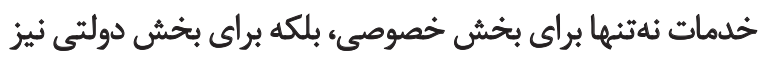

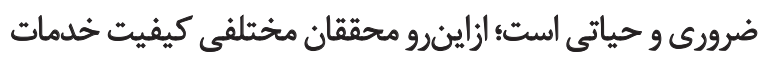

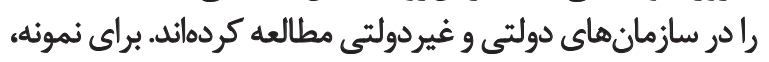

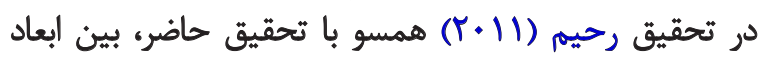
مختلف كيفيت شكاف وجود دارد.

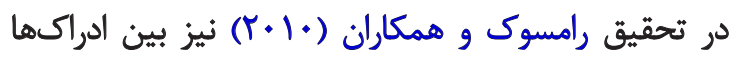

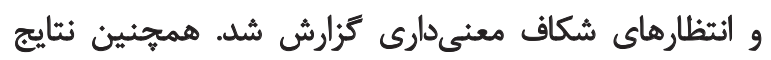

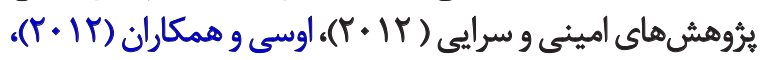

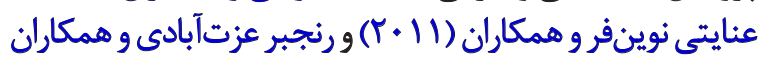

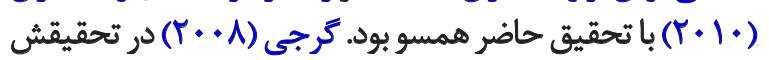

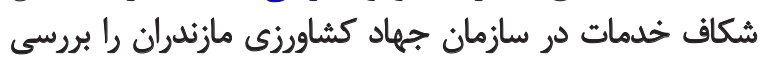

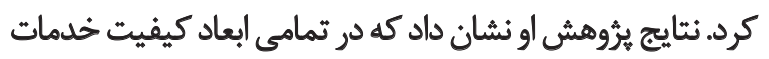

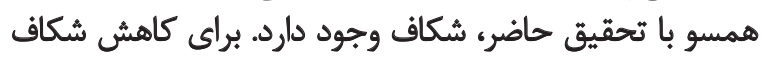

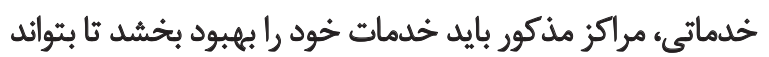

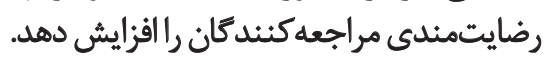

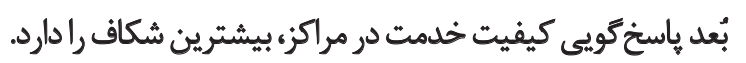

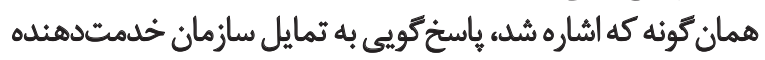

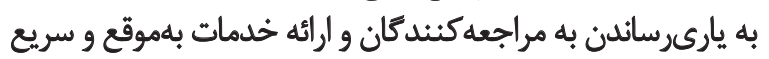

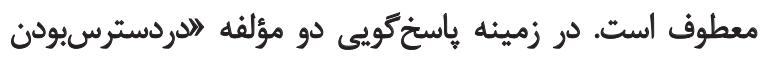

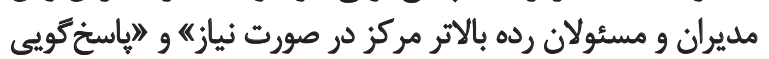

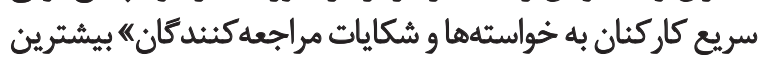

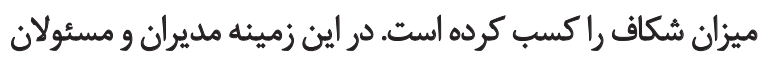

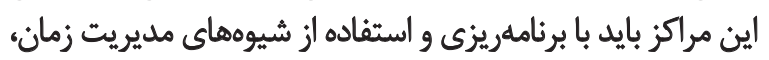

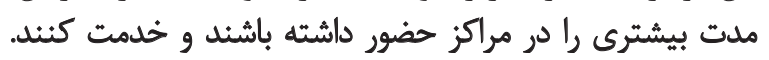

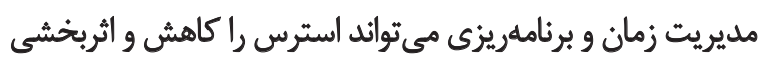
مديران را افزايش دهد (Rahim \& Nasir, 2011).

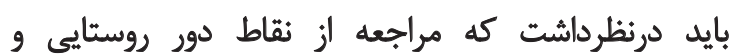

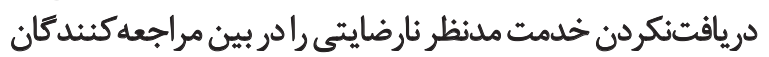

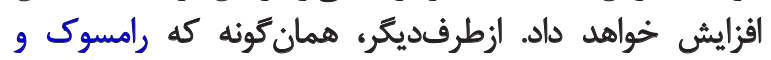

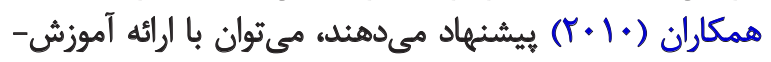

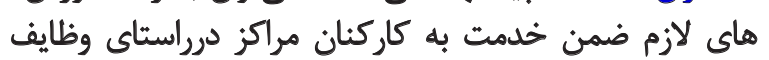

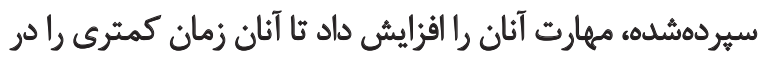
خدمترسانى به مراجعه كنيدكان صرف كران كنئن 


\section{References}

Agholor, I. A., Monde, N., Obi, A., \& Sunday, O. A. (2013). Quality of extension services: a case study of farmers in Amathole. Journal of Agricultural Science, 5(2), 204-14.

Anaza, N. A., Rutherford, B. N., \& Widdows, R. (2012). Factors influencing perceptions of service quality in cooperative extension workers. Journal of Extension, 50(3). Retrieved from http:/ /www. joe.org/joe/2012june/rb3.php

Babiarz, P., Piotrowski, M., \& Wawrzynkiewicz, M. (2003). The application of service quality GAP model to evaluate the quality of blended learning. Paper presented at the IADIS International E-Society Conference, Lisbon, Portugal, 3-6 June 2003.

Bagherzadeh, M., \& Bagherzadeh, F. (2010). [Evaluating the service quality of higher education centers in Tabriz using SERVQUAL model and ranking the centers using Hierarchical Analysis Process (Persian)]. Instruction and Evauation, 2(8), 31-54

Bakar, C., Seval Akgün, H., \& Al Assaf, A. F. (2008). The role of expectations in patients' hospital assessments: A Turkish university hospital example. International Journal of Health Care Quality Assurance, 21(5), 503-16.

Beatson, A., Lings, I., \& Gudergan, S. (2008). Employee behaviour and relationship quality: impact on customers. Service Industries Journal, 28(2), 211-23.

Berry, L. L., Parasuraman, A., \& Zeithaml, V. A. (1988). The servicequality puzzle. Business Horizons, 31(5), 35-43.

Blanchard, R. F., \& Galloway, R. L. (1994). Quality in retail banking. International Journal of Service Industry Management, 5(4), 5-23.

Brown, S. W., \& Swartz, T. A. (1989). A gap analysis of professional service quality. Journal of Marketing, 4(3), 92-98.

Clow, K. E., Kurtz, D. L., \& Ozment, J. (1998). A longitudinal study of the stability of consumer expectations of services. Journal of Business Research, 42(1), 63-73.

Cronin, J. J., Brady, M. K., \& Hult, G. T. M. (2000). Assessing the effects of quality, value, and customer satisfaction on consumer behavioral intentions in service environments. Journal of Retailing, 76(2), 193-218.

Enayati Novinfar, A., Uosefi, M., Siyami, L., \& Javaheri Daneshmand, M. (2011). [Evaluation of the quality of education services of Payam-e Noor University of Hamedan based on the SERVQUAL model (Persian)]. Journal of Research and Planning in Higher Education, 17(3), 135-51.

Feali, S., Biglari, N., \& Pezeshki Rad, Gh. (2011). [Students' satisfaction of the quality of educational services (using SERVQUAL model) in college of agriculture, Tarbiat Modares (Persian)]. Iranian Journal of Agricultural Economics and Development Research, $42(4), 199-207$.

Gorji, M. B. (2008). [A service quality survey and its relationship to effectiveness (Persian)]. Scientific Journal of Management, 5(12), $1-11$.

Kavandi, R., \& Shakeri, F. (2011). [Promoting Iran Khodro customers' satisfaction of sale and guarantee services: an analysis of the map of quality elements via servqual approach (Persian)]. Journal of Industrial Management Faculty of Humaities, 5(14), 43-54.

Mirfakhradini, H., Mirfakhradini, F. S., \& Sadr Bafghi, M. (2013). [Investigating rate of Iatric tourisms' satisfaction and prioritizing the

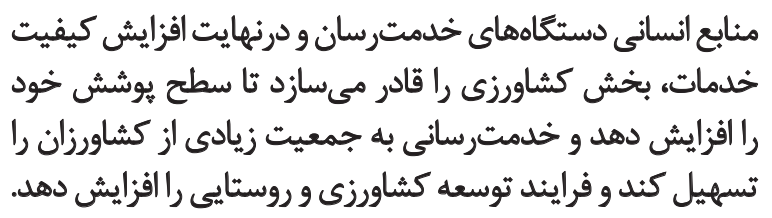


effective factors on it via fuzzy TOPSIS approach (Persian)]. Journal of Shahid Sadoughi University of Medical Sciences, 20(5), 668-78.

Ranjbar Ezzatabadi, M., Bahrami, M. A., Zare Ahmadabadi, H., Nasiri, S., Arab, M., Hadizadeh, F., et al. (2010). [Gap analysis between perceptions and expectations of service recipients through servqual approach in Yazd, Afshar Hospital (Persian)]. Toloo-eBehdasht, 9(2-3), 75-86.

Cody, K., \& Hope, B. (1999). EX-SERVQUAL: an instrument to measure service quality of extranets. Paper presented at the $10^{\text {th }}$ Australasian Conference on Information Systems. New Zeland, Wellington, 1-3 December 1999.

Headley, D. E., \& Bowen, B. D. (1997). International airline quality measurement. Journal of Air Transportation World Wide, 2(1), 55-63.

Horri, M. S., Nouri, I., Ehsanifar, M., \& Hadavand, F. (2012). Customer satisfaction survey for governmental organizations (Case study: Markazi Province Agricultural Jihad Organization). American Journal of Scientific Research, 54, 81-91.

Huy, N. Q., Tam, P. T., \& Nga, L. P. (2015). Determinants of corporate customer satisfaction in service quality at Vietnam bank for agriculture and rural development. Kaav International Journal Of Economics, Commerce \& Business Management, 2(3), 15. Available from: http://www.kaavpublications.org/ journals/journal-1/abstract/abstract-352.pdf

Landrum, H., Prybutok, V. R., Kappelman, L. A., \& Zhang, X. (2009). Services: a parsimonious instrument to measure service quality and information system success. Quality Control and Applied Statistics, 54(1), 123-24.

Lewis, R. C., \& Booms, B. H. (1983). The marketing aspects of service quality. In L. Berry, G. Shostack, \& G. Upah (Eds.), Emerging Perspectives on Services Marketing (pp. 99-107). Chicago: American Marketing Association.

McClelland, S. D. (2002). Training needs assessment for the united way of Dunn County Wisconsin. Journal of Human Resource, 5(6), $153-67$.

Mmbengwa, V. M., Groenewald, J. A., Van Schalkwyk, H. D., \& Sebopetsa, M. P. (2012). An evaluation of the quality of government extension services in West Coast District of Western Cape Province, RSA. OIDA International Journal of Sustainable Development, $4(12), 113-26$.

Osei Mensah, J., Owusu Damoah, E, \& Aidoo, R. (2012). Assessing farmers' satisfaction of agronomic services received in Ghana using the SERVQUAL model: a case study of Kumasi metropolis. International Journal of Business and Social Science, 3(19), 51-60.

Parasuraman, A., Zeithaml, V. A., \& Berry, L. L. (1994). Reassessment of expectations as a comparison standard in measuring service quality: implications for future research. Journal of Marketing, 58, 111-24.

Parasuraman, A., Zeithaml, V. A., \& Berry, L. L. (1988). Servqual: a multiple item scale for measuring consumer perceptions of service quality. Journal of Retailing, 64(1), 12-37.

Parasuraman, A., Zeithaml, V. A., \& Malhotra, A. (2005). ES-QUAL: a multiple-item scale for assessing electronic service quality. Journal of Service Research, 7(3), 213-33.

Rahim, R. C., \& Nasir, N. (2011). The measurement of service quality using SERVQUAL: the case study of Peladang Setiu Agro Resort, Terengganu, Malaysia. Innovation, Development Sustainability, and Economic Growth, 1112-127.
Ramseook-Munhurrun, P., Lukea-Bhiwajee, S. D., \& Naidoo, P. (2010). Service quality in the public service. International Journal of Management and Marketing Research, 3(1), 37-50.

Rana, A. S., Reddy, G. P., \& Sontakki, S. (2013). Perceived service quality of agricultural organizations comparative analysis of public \& private sector. International Journal of Advanced Research in Management and Social Sciences, 2(1), 286-95.

Terry, B. D., \& Israel, G. D. (2004). Agent performance and customer satisfaction [Internet]. Journal of Extension, 42(6). Retrieved from http://www.joe.org/joe/2004december/a4.php

Wisniewski, M. (2001). Using SERVQUAL to assess customer satisfaction with public sector services. Managing Service Quality: An International Journal, 11(6), 380-88.

Zeithaml, V. A., Parasuraman, A., \& Berry, L. L. (1985). Problems and strategies in services marketing. Journal of Marketing, 49, 3346 .

Zeithaml, V. A., Parasuraman, A., \& Berry, L. L. (1990). Delivering quality service. New York: Free Press. 